\title{
Control algorithm for emission test simulation
}

\author{
S. B. Ayati ${ }^{1^{*}}$, H. A. Nozari ${ }^{2^{* *}}$, A. Ordys ${ }^{1}$ and G. Collier ${ }^{1}$ \\ ${ }^{1}$ School of Mechanical and Automotive Engineering, Faculty of Engineering, Kingston University, London, UK \\ ${ }^{2}$ Department of Electrical Engineering, Islamic Azad University, Joybar Branch, Joybar, Iran \\ "Sbhayati@yahoo.com, Hasan.abbasi.nozari@gmail.com
}

\begin{abstract}
Automobiles are one of the main sources of global pollution. In order to prevent manufacturing of cars with high pollution, appropriate institutions are performing standard emission tests before the final product is released in the market. Recently, some robots and electronic devices are dedicated to perform such tests instead of human drivers. In this paper, simulation of the vehicle with the brake and the throttle as inputs, and the velocity, the position and the main components of exhaust gas as outputs in the emission test circumstances is discussed. The main components of exhaust gas are measured during the simulation. The performance of a nonlinear fuzzy controller and a conventional PID controller are compared to control the vehicle in such a test.
\end{abstract}

Keywords. Power train, emission tests, fuzzy, PID, automated test driving.

\section{Introduction}

Nowadays, one of the most important issues in the car industry is the exhaust emissions of the vehicles, which have caused intolerable pollution of many cities. Automobiles are one of the main sources of global pollution. The most polluting daily activity of an average person is car driving. The power to move a car comes from burning fuel in an engine. Pollution from cars comes from products of this combustion process (Automobile Emissions, 1994). Generally, in order to prevent manufacturing of cars with high pollution, appropriate institutions are performing standard tests before the final product is released in the market (Bauer, 1996).

Brain, hands, legs and all incredible connections make humans the most notable powerful tool to ponder, make decisions, manage, and hence perform those tests. However, humans have caused some prevalent errors, which prevent precise and repetitive execution of driving tasks. In order to achieve this, robots are being considered to take over this remarkable role in the modern car industry. Although Automation testing in vehicles is increasing, human drivers are still executing testing of these vehicles.

This paper proposes the simulation of the vehicle model and associated control strategies for test driving. A simulation model of the vehicle has been presented. Fuzzy and PID controllers are being used to track the desired speed as per test cycle, which is defined by the relevant legislations. Fuzzy controller has been designed and compared with PID controller. The pollutant measuring procedures are simulated.

Test procedures

The automotive manufacturers spend millions of pounds each year applying road tests to ensure safety, control performance and compare the data with the other vehicles already available in the market. In order to perform such tests, the vehicle should track the desired speed according to the speed cycles, defined by legislations describing standard conditions for measurement of the rate of pollutants and associated parameters.

Gasoline and diesel fuels are a mixture of hydrocarbons. In perfect engine combustion, oxygen from the air would convert all hydrogen from the fuel into water and all carbon to carbon dioxides. In reality, the combustion process cannot be perfect and automotive engines emit several types of pollutants (Automobile Emissions, 1994). Exhaust pollutants include hydrocarbon $(\mathrm{HC})$, Nitrogen oxides $\left(\mathrm{NO}_{\mathrm{x}}\right)$, carbon monoxide (CO), and carbon dioxide $\left(\mathrm{CO}_{2}\right)$ (Bauer, 1996, Automobile Emissions, 1994). The first CARB legislation was introduced in 1960s, by California. Legislators define permissible limits and testing procedures. In order to control producing pollutions from engine and vehicles, the Clean Air Act of 1970 gave EPA broad authority to regulate vehicle pollution (Automobile Emissions, 1994).

CARB legislation, EPA legislation, EU legislation, and Japanese legislation are the primary emission-control legislations. Legislations define their emission control standards and test cycles for different vehicle categories, and specified emission limits for particular pollutants. Pollution testing is nowadays performed by manufacturers as part of the quality control procedures. For granting General Certification for a vehicle, type approval is performed and test cycles must be driven

Fig.1. EUDC cycle

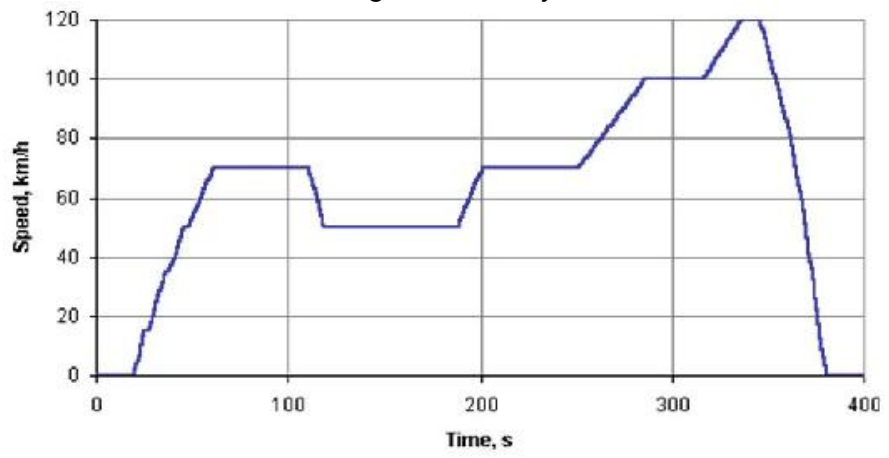

Ayati et al. Indian J.Sci.Technol. 
under specific operating condition and emission limits must be complied with (Bauer, 1996).

Fig. 2. FTP75 cycle

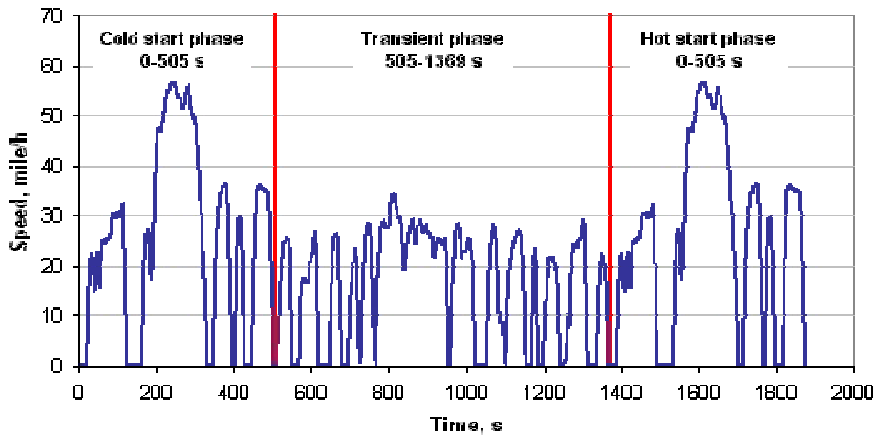

Fig. 3. Schematic model of the power train (Ofria C. 2009. www.familycar.com/Transmission.htm. July

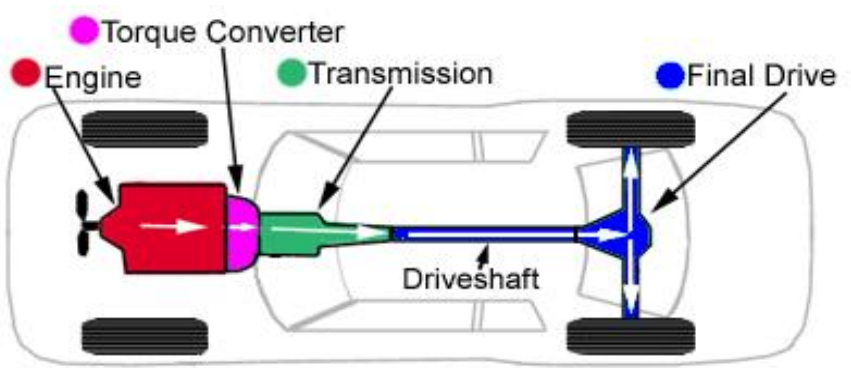

This paper simulates a passenger car under the European Union Cycle named EUDC, based on the prescribed vehicle velocity profile, shown in Fig. 1, and also the first phase of the United States Cycle named FTP75, shown in Fig. 2.

Fig. 4. Model of the vehicle

\section{Modelling the vehicle}

In order to simulate the vehicle under emission test, the vehicle model contains the Brake and the Throttle as the inputs to the model and the velocity and pollutants as the model outputs. As emission tests are performed in a straight line, the longitudinal model of the vehicle is considered, ignoring any effect of the steering wheel. The schematic of the power train is shown in Fig. 3.

The relations have been derived from Newton's second law of motion. The vehicle is modelled using the standard equations from (Kiencke \& Nielsen, 2005, Matlab, using simulink), summarised here and the model is shown in Fig. 4.

Engine

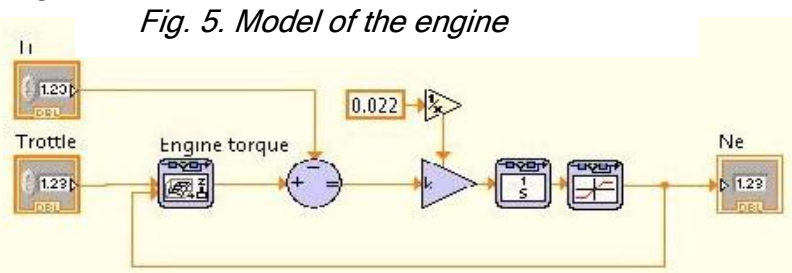

The engine input is the throttle opening as directed by the driver. The appropriate engine torque is selected from the engine map (look up table), which depends on the throttle opening and the current engine speed. The model of the engine is pictured in Fig. 5.

$l_{s i} N_{t}=T_{t}-T_{i}(1)$

$T_{i}=T_{\text {map }}\left(\right.$ throttle, $\left.N_{i}\right)(2)$

\section{Transmission}

The transmission is modelled as the static gear ratio, where the transmission gear ratio is the function of the

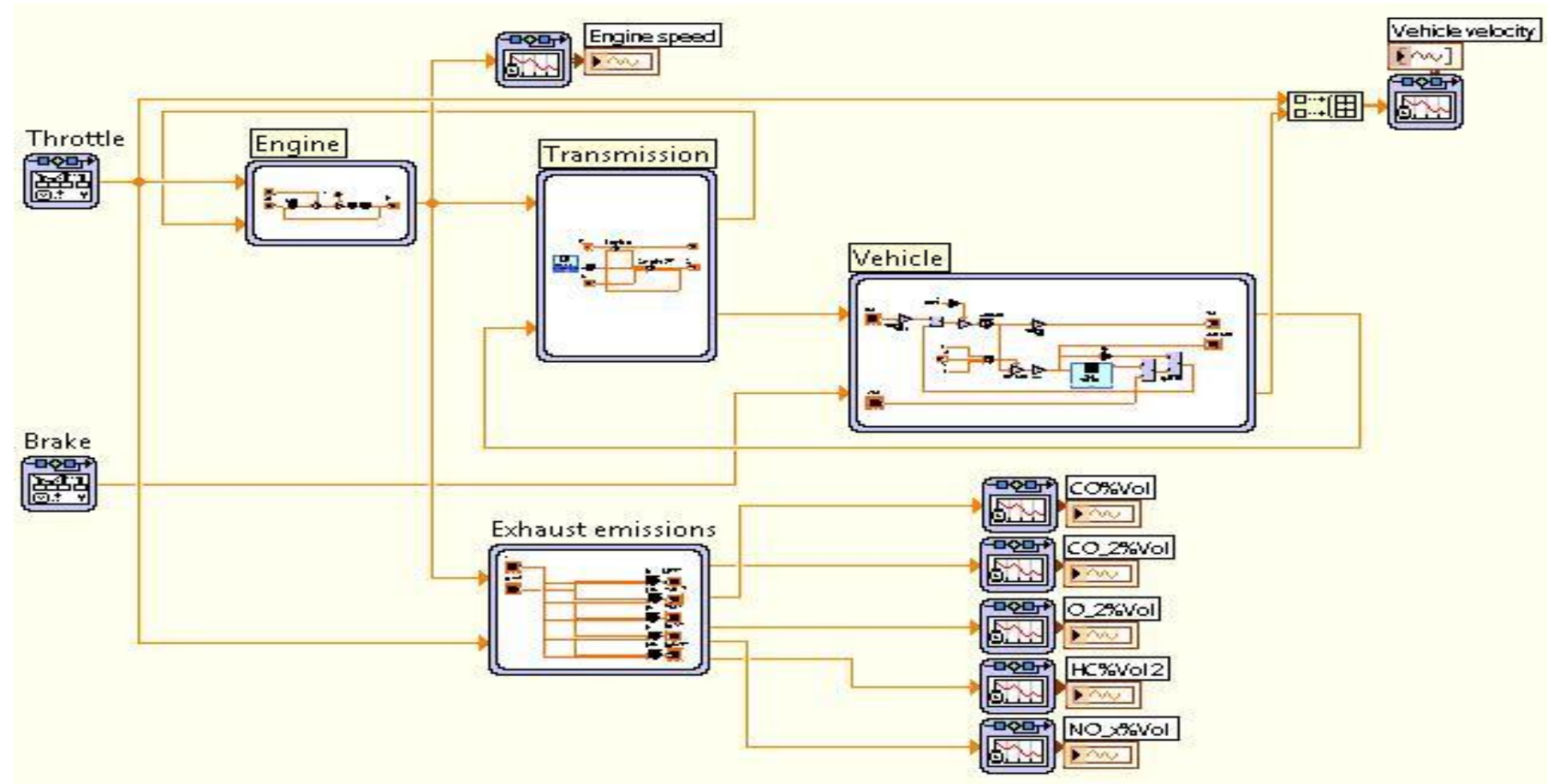


current gear and the ratio of the transmission input and output torque and engine speed.

$$
\begin{aligned}
& T_{\mathrm{i}}=\left(N_{\mathrm{s}} / f\left(\frac{\mathrm{i}_{g} N_{\text {gut }}}{N_{a}}\right)\right)^{2} \\
& T_{\text {out }}=i_{g} T_{\mathrm{i}} f\left(\frac{\mathrm{i}_{g} N_{\text {gut }}}{N_{a}}\right) \\
& i_{g}=f(g \text { onr })
\end{aligned}
$$

Vehicle dynamic

The vehicle dynamics contains the final drive and the dynamic load.

$I_{v} N_{1:}=i_{f}\left(T_{\text {out }}-T_{\text {load }}-T_{B}\right)$

The vehicle is affected by the following longitudinal forces, acting on it as a load torque.

Aerodynamic drag: $F_{a}$, is modelled as proportional to the

front $A_{\mathrm{a}}$ area and the square of the vehicle velocity $\mathrm{v}$

with the proportionalityconstant $c_{\mathrm{w}}$, where $\rho_{\mathrm{a}}$ is air density.

$F_{a}=\frac{1}{2} c_{\mathrm{W}} A_{a} p_{a} v^{2}(7)$

Rolling resistance: $\mathrm{F}_{\mathrm{F}}$, is modelled with the rolling

resistance coefficient $c_{\mathrm{T}}$, vehicle mass mand the road

slope aas:

$F_{\mathrm{r}}=c_{\mathrm{r}} m g \cos \alpha(8)$

\subsubsection{Gravitational}

$F_{g}$, is modelled with the road slope aand mas the mass of the vehicle:

$F_{g}=m g \sin \alpha(9)$

Exhaust emissions
Vol. 5 No. 4 (Apr 2012)

ISSN: 0974- 6846

The vehicle model contains an exhaust emissions part to measure the pollutants during the test. This model measures $\mathrm{CO}, \mathrm{CO}_{2}, \mathrm{O}_{2}, \mathrm{HC}$, and $\mathrm{NO}_{\mathrm{x}}$ under standard test cycles. $\mathrm{CO}, \mathrm{CO}_{2}$, and $\mathrm{O}_{2}$ are measured in volume percent and $\mathrm{HC}$ and $\mathrm{NO}_{\mathrm{x}}$ are measured in parts per million of carbon.

\section{Controller Design}

As the system dynamics is nonlinear, controlling the vehicle is not simple. PID controller is a linear controller and much simpler than other controllers, but it is not expected to control the vehicle very well (Zetterqvist, 2007). Therefore the nonlinear fuzzy controller is developed. The comparison between the controllers is presented.

PID control

Easy understanding and implementation makes PID controller the most popular controller in the industry. The controller input signal is the error between the desired and the reference signal. The control signal is generated in PID controller by (10) (Zetterqvist, 2007).

$$
u_{\mathrm{t}}=K\left(e(t)+\frac{1}{\tau_{p}} \int_{t_{D}}^{t} e_{\mathrm{T}} d \tau+T_{D} \frac{d t(t)}{d t}\right)
$$

PID controllers are difficult to tune when the process dynamic or disturbance is not known precisely. To improve PID performance LabVIEW autotuning PID is applied. This package uses Ziegler and Nicolas' heuristic methods for determining the parameters of the PID controller (National Instruments). The design of PID controller in LabVIEW is pictured in Fig. 6. Fuzzy control

As we consider a replacement for the human driver, fuzzy control is a better solution, being closer to human performance. Fuzzy control is a method based on a set of linguistic rules. Designing a fuzzy controller consists of

Fig. 6. PID Controller

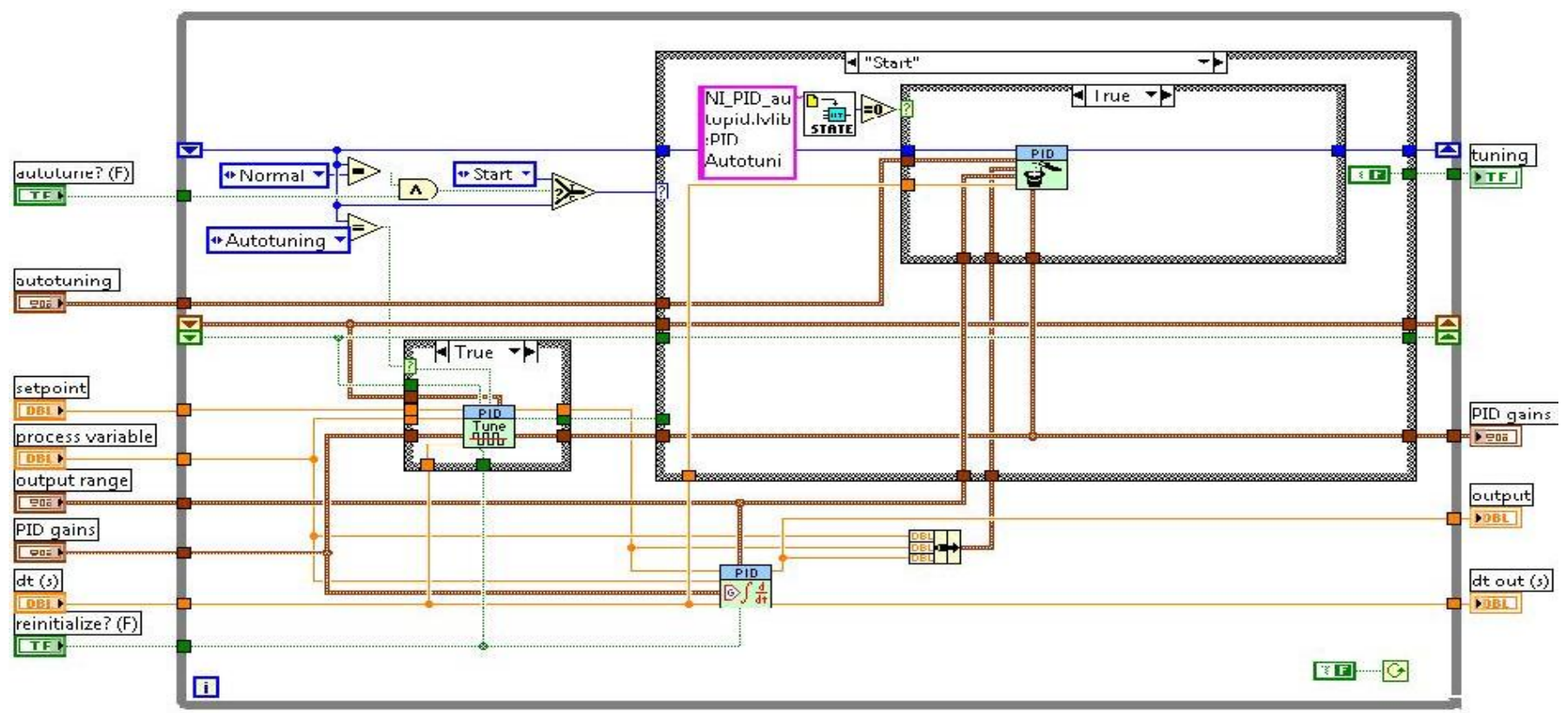


Fig.7. Fuzzy Controller

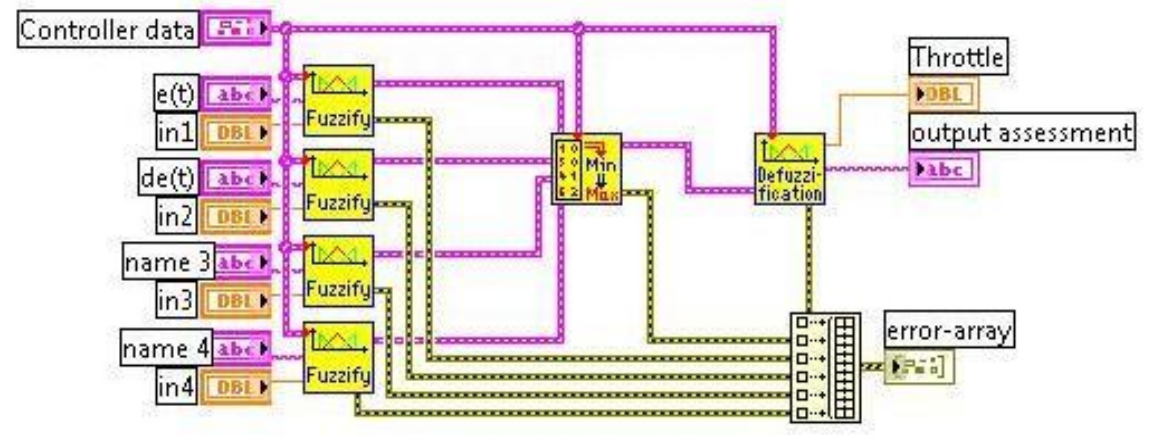

Vol. 5 No. 4 (Apr 2012) ISSN: 0974- 6846

\section{Results and Controller Comparison} The step response comparison

The step response of the model which has been controlled by PID is shown in Fig. 9, and the step response of the model with the fuzzy controller is shown in Fig. 10.

\section{Velocity tracking comparison}

First of all, the results of applying the EUDC cycle are considered, and then the first phase of FTP75 cycle is applied and the results are shown, for both controllers considered in this paper.

Tracking the vehicle under EUDC
Defuzzification (Rajase\& Vijay, 2007).

Variables are translated into mathematical expressions by membership functions in the Fuzzificationstep, before defining the rules between input and output signals, to generate the output in Fuzzy rules step. Control strategy has been defined by using IFTHEN Rules (Fig.8) (Zetterqvist, 2007, National Instruments).

Finally, Defuzzification takes the output from Fuzzy

\begin{tabular}{|l|l|l|l|}
\multicolumn{4}{c|}{ Fig. 8. Brake and throttle Fuzzy rules } \\
\begin{tabular}{|l|l|l|l|}
\hline Rule No. & IF e(t) & AND de(t) & THEN Brake \\
\hline 1 & Neg & Neg & GP \\
2 & Neg & Zero & GP \\
3 & Neg & Pos & GP \\
4 & Zero & Neg & P \\
5 & Zero & Zero & Z \\
6 & Zero & Pos & P \\
7 & Pos & Neg & Z \\
8 & Pos & Zero & Z \\
9 & Pos & Pos & Z \\
\hline Rule No. & IF e(t) & AND de(t) & THEN Throttle \\
\hline 1 & Neg & Neg & Z \\
2 & Neg & Zero & Z \\
3 & Neg & Pos & Z \\
4 & Zero & Neg & Z \\
5 & Zero & Zero & Z \\
6 & Zero & Pos & P \\
7 & Pos & Neg & Z \\
8 & Pos & Zero & GP \\
9 & Pos & Pos & P \\
\hline
\end{tabular}
\end{tabular}

rules and converts it to numerical value to be sent to the process under control. The most common method of Defuzzification applied to closed-loop control applications is Centre of Gravity (CoG). At first the typical value of the terms in the linguistic output variable is determined. Secondly, the best compromise is calculated with a weighted average of typical values of terms (Zetterqvist, 2007, National Instruments).

As the desired vehicle speed value is known, the speed error and derivative of this error are defined as controller inputs. Two fuzzy controllers are applied independently for the brake and throttle control. The design of the fuzzy controller in LabVIEW is pictured in Fig. 7 and the rules are illustrated in Fig. 8. cycle in terms of vehicle velocity shown in Fig. 11 appears to produce the same results, for both PID and fuzzy controller. However, a more detailed comparison of the errors shown in Fig. 12 shows less of an error with fuzzy control.

Fig.9. Step response of the model when applying PID controller

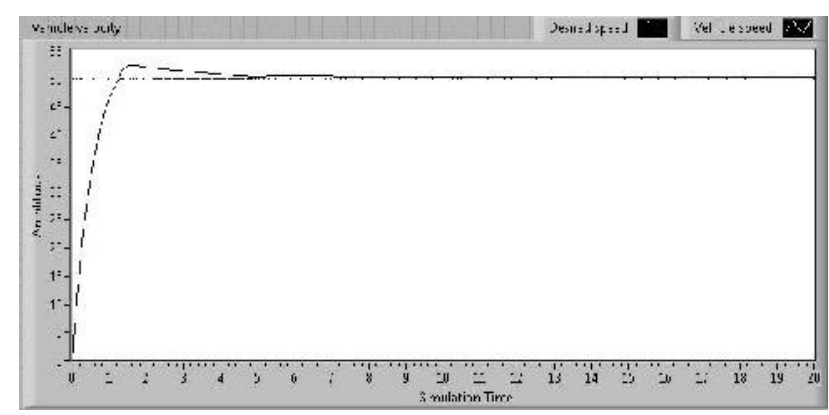

Fig. 10. Step response of the model when applying Fuzzy controller

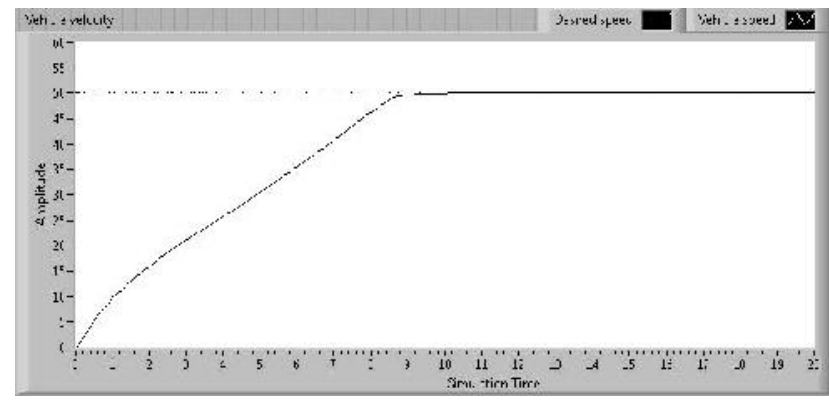

Fig. 11. EUDC response of the vehicle

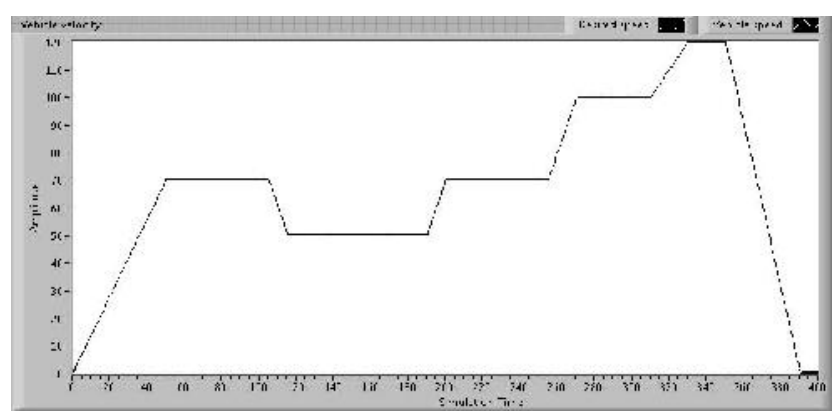


Fig. 12. Vehicle velocity error for EUDC test cycle when applying a. PID; b. Fuzzy controller

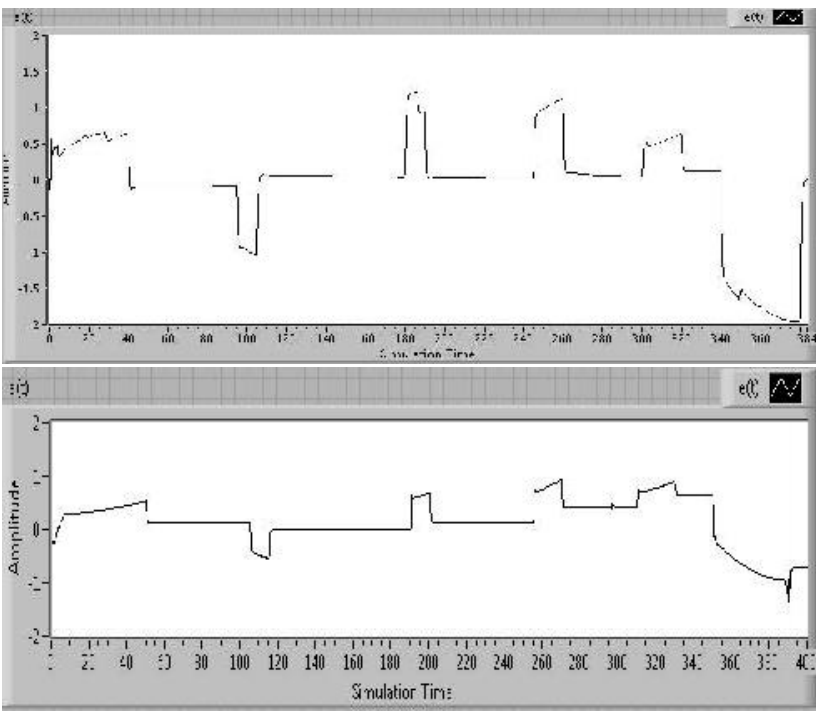

Fig. 13. First phase FTP75 response of the vehicle

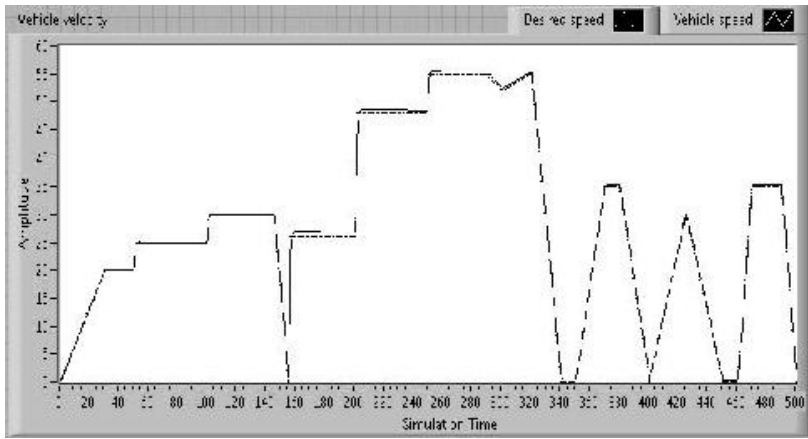

Fig. 14. Vehicle velocity error for FTP75 test cycle when applying a. PID b. Fuzzy controllers

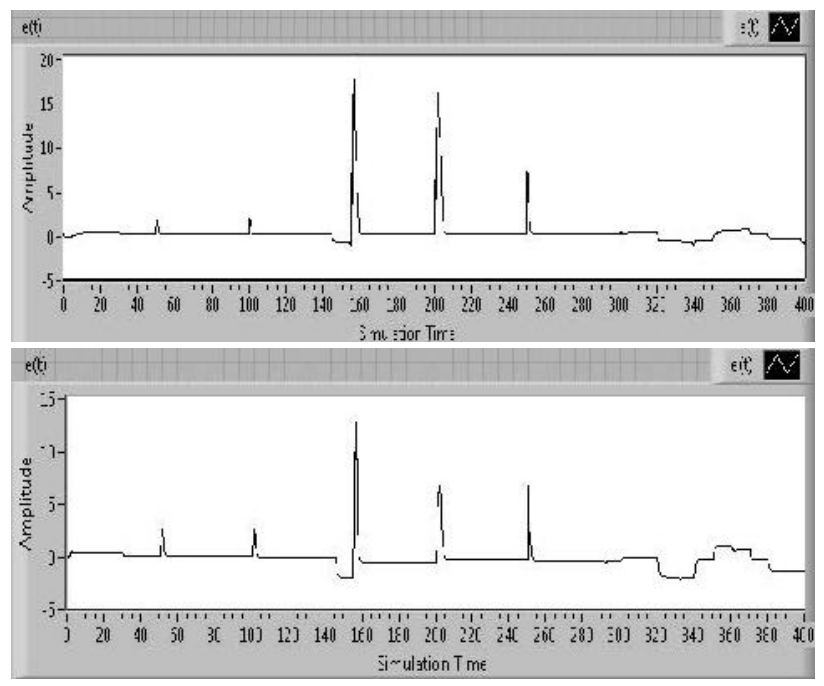

Vol. 5 No. 4 (Apr 2012)

ISSN: 0974- 6846
Fig. 15. Measurements of $\mathrm{CO} \& \mathrm{CO}_{2}$ under EUDC cycle when applying PID controller

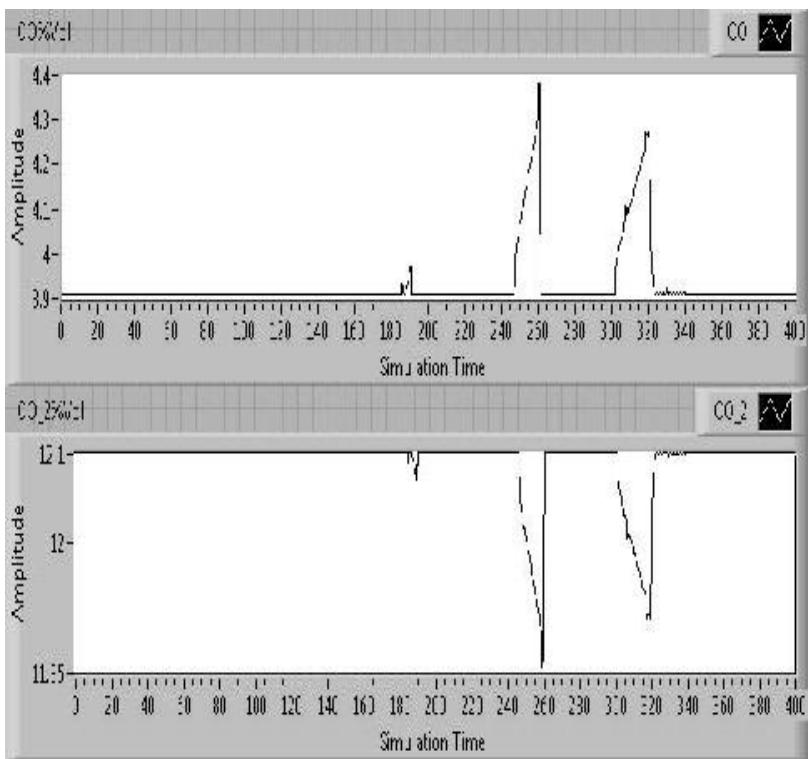

Fig. 16. Measurements of $H C \& \mathrm{NO}_{x}$ under EUDC cycle when applying PID controller

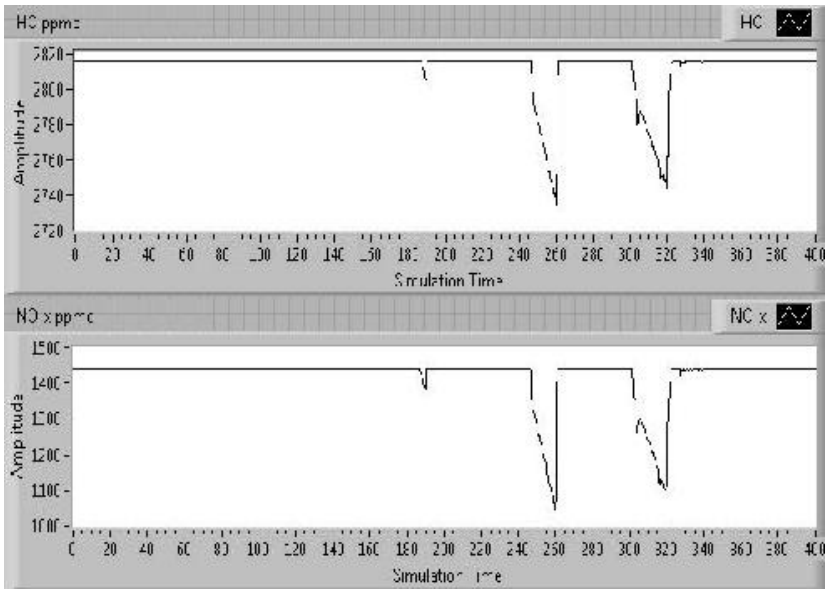

Fig. 17. Measurements of $\mathrm{CO} \& \mathrm{CO}_{2}$ under EUDC cycle when applying Fuzzy controller

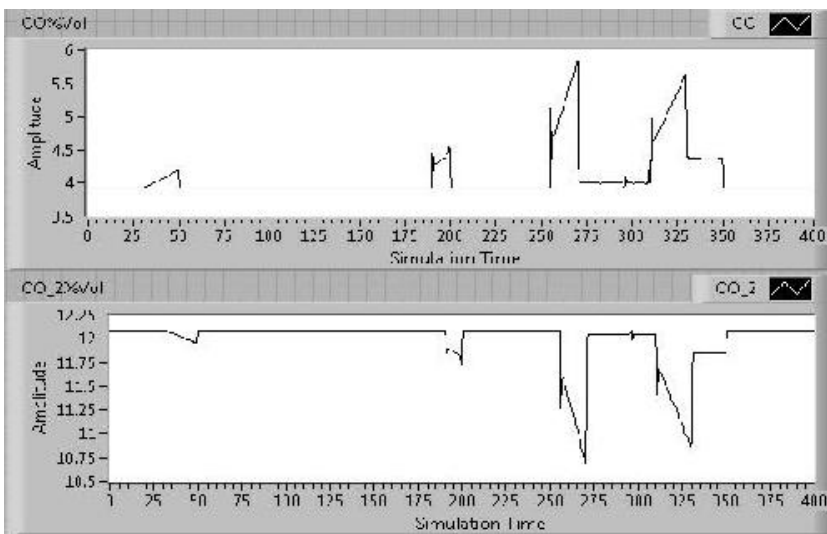

Research article

COIndian Society for Education and Environment (iSee)
"Algorithm for emission test" http://www.indjst.org
Ayati et al. Indian J.Sci.Technol. 
Fig. 18. Measurements of $\mathrm{HC} \& \mathrm{NO}_{x}$ under EUDC cycle when applying Fuzzy controller

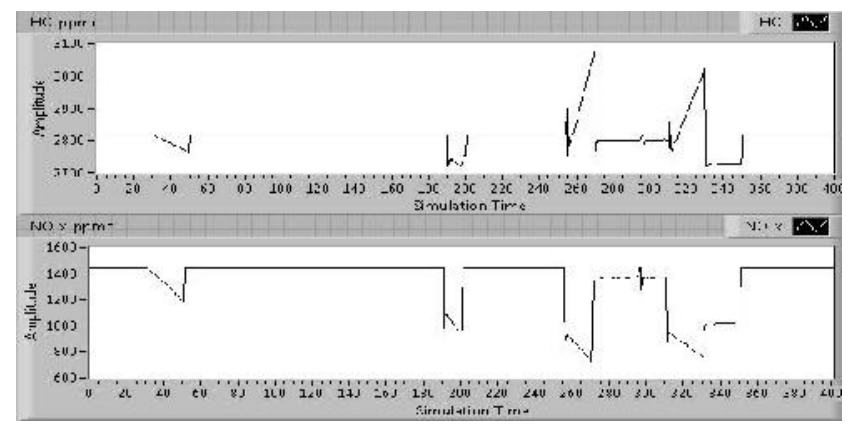

Fig. 19. Measurements of $\mathrm{CO} \& \mathrm{CO}_{2}$ under FTP75 cycle when applying PID controller

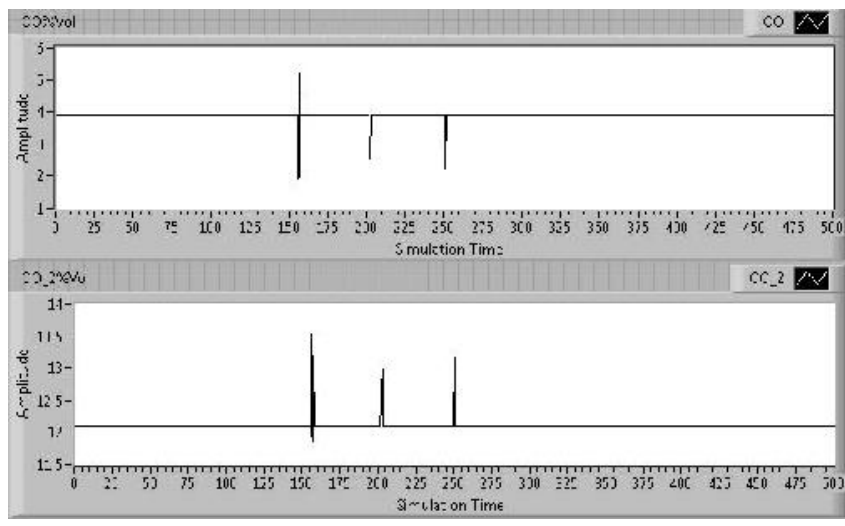

Fig. 20. Measurements of HC \& NO under FTP75 cycle when applying PID controller

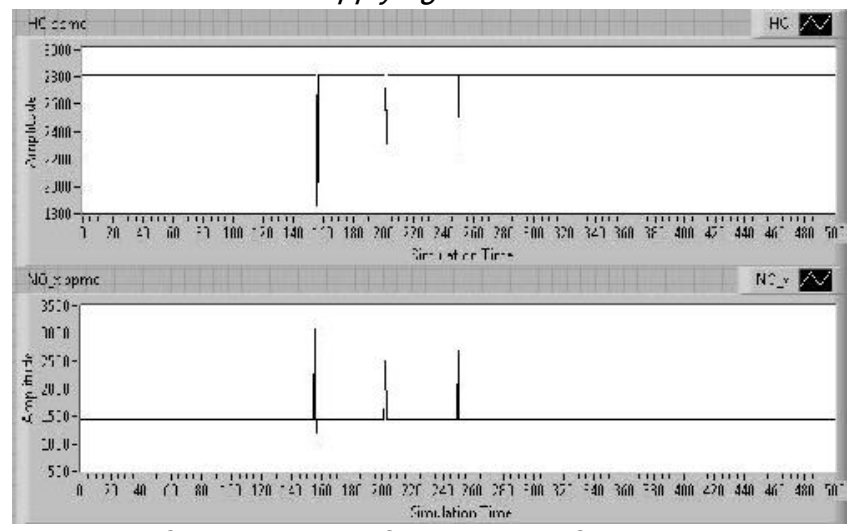

The results of applying the first phase of FTP75 cycle are demonstrated. The vehicle which tracks the cycle in terms of vehicle velocity is shown in Fig. 13. Similar to the results from EUDC cycle, the vehicle has been controlled well by PID controller as well as fuzzy controller here and the detailed error comparison it is shown in Fig. 14, again in favour of fuzzy controller.

Exhaust emissions comparison, EUDC cycle

During the test under EUDC cycle, the particular pollutants are being measured. The results of $\mathrm{CO}$ and $\mathrm{CO}_{2}$ measurementsare shown in Fig. 15 (in volume percent), and $\mathrm{HC}$ and $\mathrm{NO}_{x}$ measurements in Fig. 16 (in parts per million of carbon) for the vehicle with PID controller.

Research article

COIndian Society for Education and Environment (iSee)
Fig. 21. Measurements of $\mathrm{CO} \& \mathrm{CO}_{2}$ under FTP75 cycle when applying Fuzzy controller

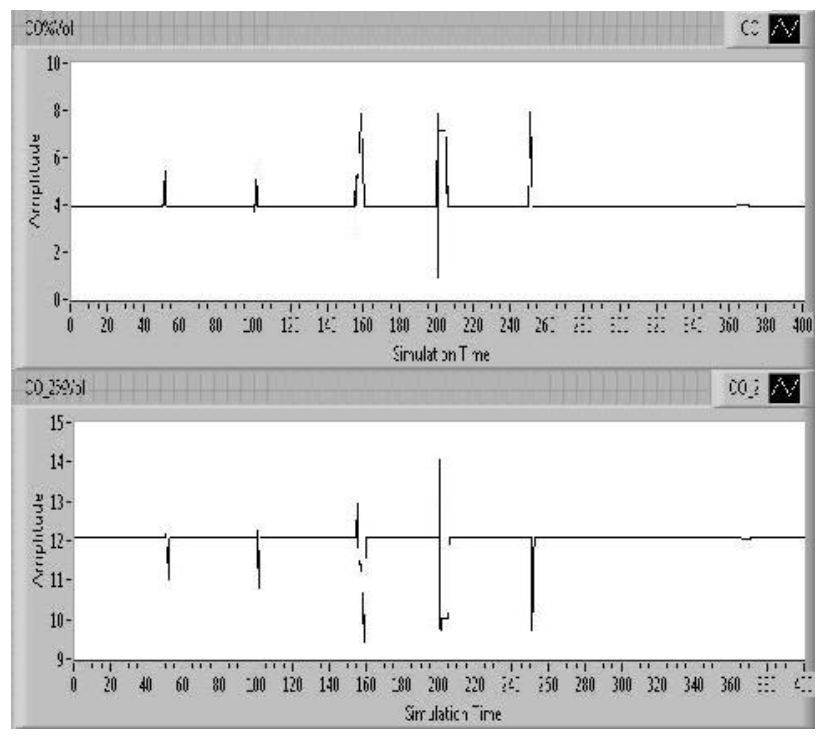

Fig. 22. Measurements of $\mathrm{HC} \& \mathrm{NO}_{x}$ under FTP75 cycle when applying Fuzzy controller

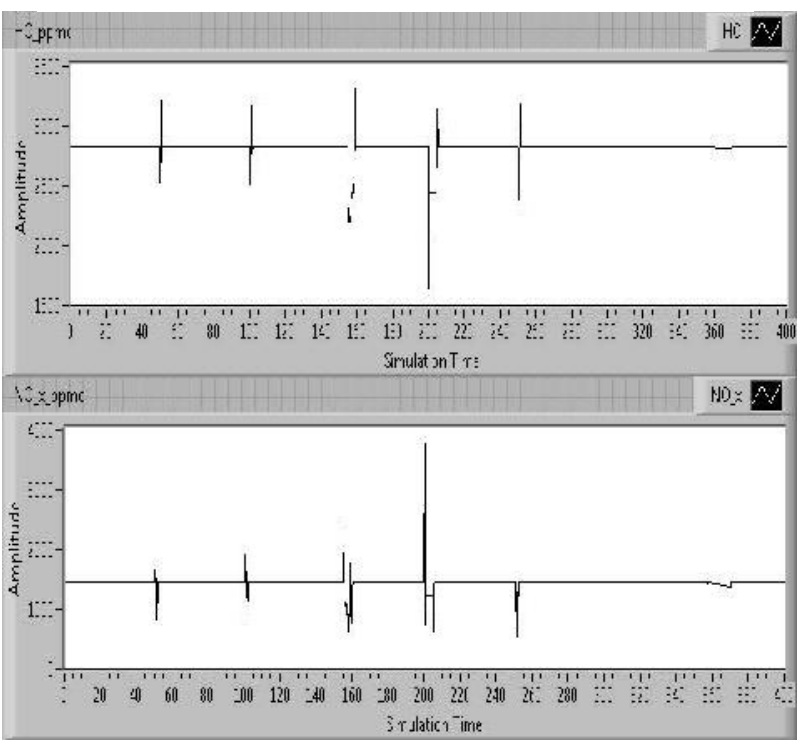

The results of $\mathrm{CO}$ and $\mathrm{CO}_{2}$ measurements are shown in Fig. 17, and the measurements of $\mathrm{HC}$ and $\mathrm{NO}_{x}$ in Fig. 18 for the vehicle with fuzzy controller.

Exhaust emissions comparison, FTP75 cycle, first phase

Under first phase of FTP75, the results of $\mathrm{CO}$ and $\mathrm{CO}_{2}$ measuring are shown in Fig. 19 (in volume percent) and $\mathrm{HC}$ and $\mathrm{NO}_{\mathrm{x}}$ measurements are shown in Fig.20 (in parts per million of carbon), for the vehicle with PID controller.

The results of $\mathrm{CO}$ and $\mathrm{CO}_{2}$ measurements are shown in Fig. 21 and the measurements of $\mathrm{HC}$ and $\mathrm{NO}_{\mathrm{x}}$ are shown in Fig.22 for the vehicle with fuzzy controller.
"Algorithm for emission test" http://www.indjst.org 


\section{Conclusion}

Due to a range of economical benefits, demand for simulating driving tests is expected to increase significantly in near future. The safety issue is the key problem in the development and performance of the automated driving tests. Thus, it is highly desirable to perform extensive and detailed simulation of the vehicle under such driving tests. In addition, the implementation and practical investigation are very expensive; therefore simulation of driving test and finding the cheapest way to control the vehicle is very effective to this problem.

A model of a passenger car with the brake and the throttle inputs and vehicle velocity and measured pollutants as outputs has been developed in LabVIEW, using simulation module. Two controllers have been developed and implemented: a PID controller and a fuzzy controller. Based on nonlinear problems, the nonlinear fuzzy controller has been designed and compared with classical PID controller in time domain. The exhaust emission tests for a passenger car have been simulated using different two tests cycles; EUDC (European Union), and FTP75 (United States).

Fuzzy controller performed very well while tracking the desired speed in both tests. It is clear in particular from the error figures that fuzzy controller was faster and reached the desired speed in superior way compared with PID controller; however, it can be said that both the fuzzy and PID controller control the vehicle well.

The levels of the pollutants throughout the tests are approximately constant and equal for both control methods, except at the points when rapid changes are demanded from the engine. At those points the PID approach produced smaller amount of emissions than fuzzy control approach.

This is due to the fact that tracking the vehicle velocity using fuzzy controller makes engine perform in more aggressive way, compared to tracking with PID controller. Thus engine has less successful combustion process and hence emits more pollutants when Fuzzy controller is used.

The vehicle model and the designed controller can be further developed for durability tests. The vehicle and controller are modelled in LabVIEW which can be easily connected to hardware for the purpose of real time testing.

\section{References}

1. Automobile Emissions (1994) An Overview. U.S. Environmental Protection Agency Office of Mobile Sources. EPA. 400-F-92-007.

2. Bauer H (1996) Automotive handbook Bosch. Robert Bosch GmbH. 4th (Ed.), ISBN 1-56091-918-3.

3. Kiencke $U$ and Nielsen $L(2005)$ Automotive control systems- for engine, driveline, and vehicle. SpringerVerlag, Berlin. pp: 425-460.

4. Using simulink and stateflow in automotive application. simulink- stateflow technical examples. pp: 8-17.
5. PID control toolkit user manual (2007) National Instruments, Lab VIEW, 372192B-01, August.

6. Rajase S and Vijay GA (2007) Neural networks, fuzzy logic and genetic algorithms, synthesis and applications. 7th Ed.,Prentice Hall of India.

7. Zetterqvist $C$ (2007) Power train modelling and control algorithm for traction control. Linkoping University, M.Sc. Thesis. 